\title{
A "popout" effect with words and nonwords
}

\author{
S. A. SORACI, JR. \\ University of Alabama, Tuscaloosa, Alabama \\ and \\ J. J. FRANKS, M. T. CARLIN, T. P. HOEHN, and J. K. HARDY \\ Vanderbilt University, Nashville, Tennessee
}

\begin{abstract}
Previous research (Flowers \& Lohr, 1985) has not found evidence for the "popout" phenomenon (e.g., Treisman, 1988) with word and nonword letter strings. Flowers and Lohr utilized a visual search task that employed a circular arrangement of stimuli. This format does not optimize spatial contiguity, which has been shown to facilitate stimulus detection in certain contexts (Bryant \& Soraci, 1992; Soraci, Carlin, Deckner, \& Baumeister, 1990). The present study examined popout with words and nonwords in a same-different task, using a visual array format in which interstimulus contiguity increased with changes in set size. With these arrays, no popout effect was evidenced under conditions of high featural overlap between targets and distractors. However, under conditions of low featural overlap, a popout effect for both words and nonwords was found.
\end{abstract}

Treisman and her colleagues (e.g., Treisman, 1988; Treisman \& Gormican, 1988) have investigated feature identification for stimuli that are coded early in visual processing. Typically, a visual search task is utilized with sets of structurally simple stimuli representing contrasting values (e.g., long vs. short) on a specific dimension (e.g., length of a line). Each stimulus value characterizes the target in one condition and the distractor(s) in the other. A feature is believed to be coded early in visual processing, or to "pop out," if it is detected with little or no increase in latency as the number of stimuli in the display increases. The assumption is that a parallel search occurs in such a display. A common finding in these studies is a marked search asymmetry for the two opposing stimulus values. For example, a long target stimulus may pop out from a set of short distractor stimuli, whereas detection of a short target among long distractors may require a serial search of the array.

Previous research (Flowers \& Lohr, 1985) has not found evidence for the popout phenomenon with word and nonword letter strings. Though a word-nonword distinction did facilitate performance in particular conditions, results indicated a serial, self-terminating search throughout. However, the visual search task utilized in this study employed a circular arrangement of stimuli. This format does not optimize spatial contiguity, which has been shown to facilitate stimulus detection in certain contexts (Bryant \&

This research was supported by the NICHD Grants 1K04 HD0092101, awarded to the University of Alabama, and R01 HD27336, awarded to the John F. Kennedy Center for Research on Education and Human Development at Vanderbilt University. Results were presented at the 32nd Annual Meeting of the Psychonomic Society, November 1991, San Francisco. Reprint requests should be sent to Sal A. Soraci, Jr., Department of Psychology, Box 870348, University of Alabama, Tuscaloosa, AL 35487-0348.
Soraci, 1992; Soraci, Carlin, Deckner, \& Baumeister, 1990).

The present study examines popout with words and nonwords in a same-different task, using a visual array format in which interstimulus contiguity increased with changes in set size. Across two experiments, recognition accuracy and search latency were measured under conditions of both high and low target-distractor featural overlap.

\section{EXPERIMENT 1}

Experiment 1 was conducted to determine whether or not a popout effect based upon the lexical status of a letter string would occur under conditions of high featural overlap.

\section{Method}

Subjects

Twelve adult volunteers from among the staff and students of Vanderbilt University served as subjects.

\begin{abstract}
Apparatus
A Hewlett-Packard Vectra personal computer was used for stimulus presentation and recording of results.

Stimuli

Stimuli were 72 pairs of four-letter strings, each pair comprising a word and a nonword. Pair members, which differed only with respect to the first letter in each string, functioned as target and distractors for one another. Each trial consisted of the presentation of 4,6 , or 8 letter strings, with the contrasting target, either a word or nonword, present on half of the trials. Stimuli were arranged in a rectangular format, their placements constant within each set size and with the middle position always blank. For example, in the 4 condition, stimuli were always presented in the four corners of the array. With this format, interstimulus contiguity is necessarily increased with changes in set size. That is, the 4 condition was low and the 8 condition was high with respect to contiguity. Examples of these arrays are presented in Figure 1.
\end{abstract}




\begin{tabular}{|c|c|c|c|c|c|c|}
\hline \multirow[b]{3}{*}{$\begin{array}{l}\text { Word Target } \\
\text { (nonword } \\
\text { surround) }\end{array}$} & \multicolumn{6}{|c|}{ Set Size } \\
\hline & \multicolumn{2}{|c|}{4} & \multicolumn{2}{|c|}{6} & \multicolumn{2}{|l|}{8} \\
\hline & $\begin{array}{l}\operatorname{gint} \\
\operatorname{gint}\end{array}$ & $\begin{array}{l}\operatorname{mint} \\
\text { gint }\end{array}$ & $\begin{array}{l}\text { fowl } \\
\text { rowl } \\
\text { rowl }\end{array}$ & $\begin{array}{l}\text { rowl } \\
\text { rowl } \\
\text { rowl }\end{array}$ & $\begin{array}{l}\text { zusy zusy } \\
\text { zusy } \\
\text { zusy busy }\end{array}$ & $\begin{array}{l}\text { zusy } \\
\text { zusy } \\
\text { zusy }\end{array}$ \\
\hline & & & & & 8 & \\
\hline $\begin{array}{l}\text { Nonword Target } \\
\text { (word surround) }\end{array}$ & $\begin{array}{l}\text { kite } \\
\text { pite }\end{array}$ & kite & $\begin{array}{l}\text { yule } \\
\text { yule } \\
\text { yule }\end{array}$ & $\begin{array}{l}\text { yule } \\
\text { yule } \\
\text { nule }\end{array}$ & $\begin{array}{l}\text { town town } \\
\text { town } \\
\text { town town }\end{array}$ & $\begin{array}{l}\text { lown } \\
\text { pown } \\
\text { town }\end{array}$ \\
\hline
\end{tabular}

Figure 1. Examples of displays used in Experiment 1 for word and nonword target trials at each of the three levels of set size.

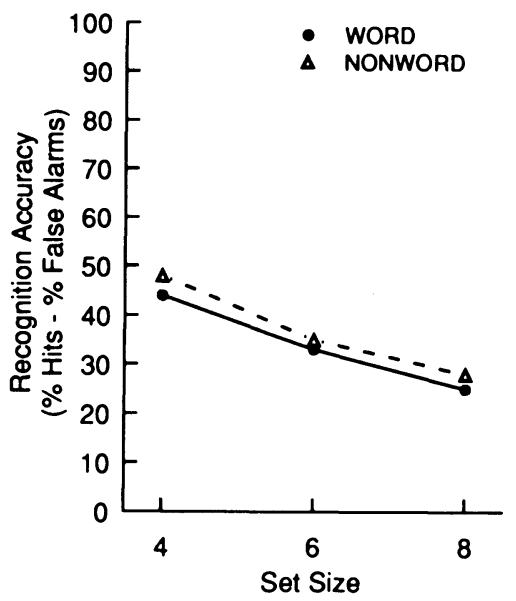

Figure 2. Mean recognition accuracy scores in Experiment 1 for word and nonword targets across the three levels of set size.

Each trial was preceded by a fixation point indicating the center of the stimulus array. The subjects initiated trials by pressing the spacebar on the keyboard. Each array was presented for $200 \mathrm{msec}$ and was followed immediately by a masking array consisting of \# signs. The subjects responded by pressing " $S$ " on the keyboard if they believed that all stimuli presented were the same, or " $D$ " if one of the stimuli differed from the others. A total of 144 trials were completed by each subject; 36 word-target present, 36 word-target absent, 36 nonwordtarget present, and 36 nonword-target absent.

\section{Design}

A 2 (target) $\times 3$ (set size) factorial design, with target (word or nonword) and set size $(4,6$, or 8$)$ as within-subjects factors, was used. The dependent variable was recognition accuracy, defined as the \% hits $\%$ false alarms.

\section{Results and Discussion}

A $2 \times 3$ analysis of variance (ANOVA) with repeated measures was performed. The only significant effect was a main effect for set size $[F(2,22)=7.95, p<.01]$, with performance in the 4 condition significantly better than that in the 8 condition (see Figure 2). This finding argues against the presence of a word-nonword popout phenomenon when targets and distractors share a high degree of featural overlap.

\section{EXPERIMENT 2}

Experiment 2 was conducted to determine whether or not a popout effect based upon the lexical status of a letter string would occur under conditions of low featural overlap.

\section{Subjects \\ Method}

Fifteen undergraduates at Vanderbilt University served as subjects.

\section{Stimuli}

Stimuli were now presented in uppercase. Target stimuli again were four-letter word and nonword strings. Nonword targets were rearrangements of the four letters in the corresponding word targets. Distractor stimuli were homogeneous, four-letter nonword strings randomly selected from the 22 letters of the alphabet not contained in the target stimulus. Such homogeneity of distractor stimuli was intended to provide a low degree of featural overlap between the target and distractors. Examples of these stimulus arrays are presented in Figure 3.

\section{Procedure}

Each subject was tested on two search tasks, with order of tasks counterbalanced.

Recognition accuracy task. Procedures in this task were identical to those in Experiment 1 with two exceptions. Because higher levels of performance were expected with low featural overlap, stimulus durations were reduced to $150 \mathrm{msec}$ in order to avoid ceiling effects. Second, word and nonword target stimuli were not presented concurrently, but in two blocks of 72 trials each. Order of presentation of these blocks was counterbalanced. The dependent variable was the same as in Experiment 1.

Search latency task. This task differed from the recognition accuracy task in that the stimulus array remained on the monitor screen until a detection response was made. The dependent variable was response latency (in milliseconds).

\section{Design and Analysis}

With regard to the recognition accuracy task, the design and analyses were identical to those used in Experiment 1. For the search latency task, a 2 (target) $\times 2$ (presence) $\times 3$ (set size) factorial design was implemented, with presence (present or absent) as an additional withinsubjects factor. A $2 \times 2 \times 3$ ANOVA with repeated measures was performed on this data.

\section{Results and Discussion}

\section{Recognition Accuracy}

The obtained main effect of target $[F(1,14)=4.59$, $p=.05]$ indicated that subjects were more accurate in

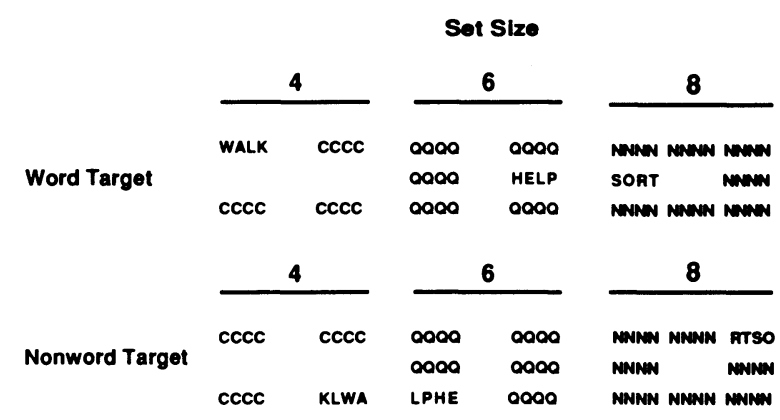

Figure 3. Examples of displays used in Experiment 2 for word and nonword target trials at each of the three levels of set size. Note the use of homogeneous nonword distractors throughout. 


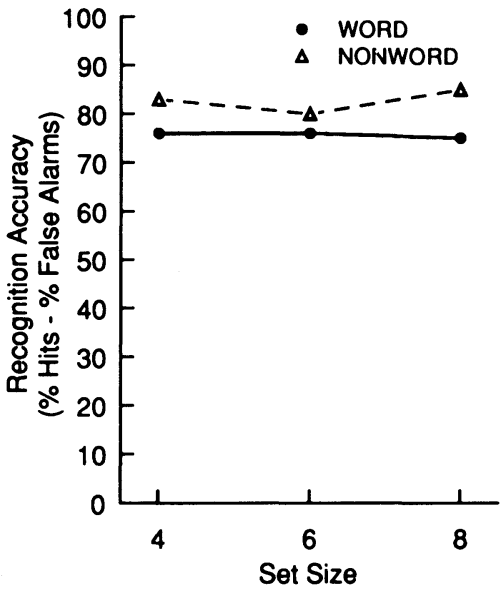

Figure 4. Mean recognition accuracy scores in Experiment 2 for word and nonword targets across the three levels of set size.

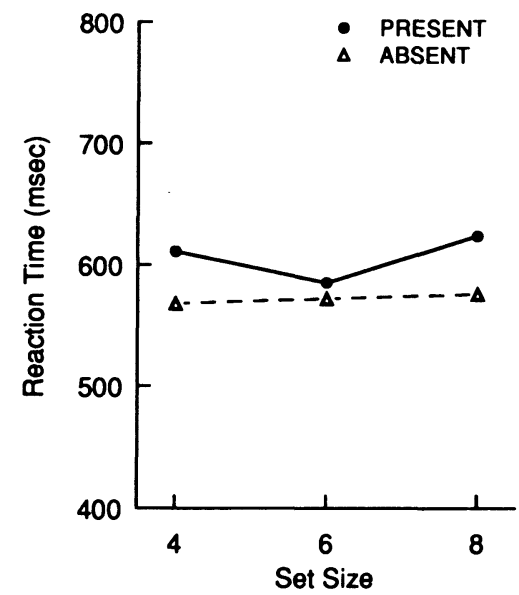

Figure 5. Mean search latencies in Experiment 2 for word targets across the three levels of set size.

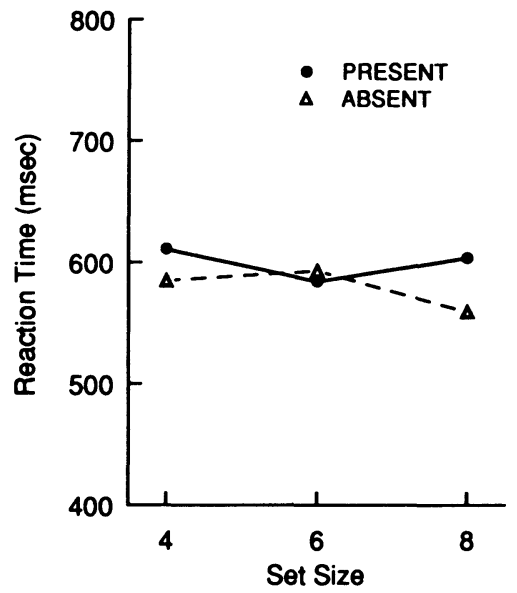

Figure 6. Mean search latencies in Experiment 2 for nonword targets across the three levels of set size. identifying nonword targets than word targets. This suggests that lexical status may influence the early stages of visual processing of linguistic stimuli, although the effect was small size and was not replicated in the search latency data. The lack of a significant set-size effect indicated that accuracy did not decrease with increases in display size (see Figure 4). This pattern of results is analogous to the popout phenomenon identified by Treisman (1982). However, in the context of the present studies, the absence of a target $\times$ set size interaction argues against lexical status of a letter string as constituting a distinct stimulus value that influences visual search.

\section{Search Latency}

The only significant effect involved the presence $\times$ set size interaction $[F(2,28)=4.29, p<.05]$, indicating that at set sizes of 4 and 8 subjects were slower to respond on trials when the target stimulus was present than on trials when the target was absent. The lack of a significant main effect of set size or a target $\times$ set size interaction suggests the presence of a popout effect for both words and nonwords, but again argues against lexical status as a distinct stimulus value that influences visual search. Latency results are presented in Figures 5 and 6.

\section{GENERAL DISCUSSION}

Under conditions of high featural overlap (i.e., Experiment 1), results indicated a serial, self-terminating search for both words and nonwords. The absence of set-size effects in Experiment 2 suggests that both word and nonword targets are searched in parallel with highly dissimilar distractor items. These findings indicate that the popout effects observed with these types of stimuli may be limited to conditions of low featural overlap. In addition, the absence of a search advantage for words versus nonwords supports the contention of Flowers and Lohr that visual search based on the lexical status of a target is a phenomenon that is fundamentally different from the effects identified by Treisman and others with more basic features of visual forms. The extent to which the popout effect observed in Experiment 2 is dependent upon an interaction of the variables of spatial contiguity, set size, and degree of featural overlap will be examined in future studies.

\section{REFERENCES}

Bryant, J. T., \& Soraci, S. A., JR. (1992). Oddity facilitation as a function of array size and spatial contiguity. Manuscript submitted for publication.

Flowers, J. H., \& LOHR, D. J. (1985). How does familiarity affect visual search for letter strings? Perception \& Psychophysics, 37, 557-567.

Soraci, S. A., Jr., Carlin, M. T., Deckner, C. W., \& Baumeister, A. A. (1990). Detection of stimulus organization: Evidence of intelligence-related differences. Intelligence, 4, 435-447.

Treisman, A. M. (1988). Features and objects: The fourteenth Bartlett memorial lecture. The Quarterly Journal of Experimental Psychology, 2, 201-237.

Treisman, A. M., \&ormican, S. (1988). Feature analysis in early vision: Evidence from search asymmetries. Psychological Review, 95, 15-48.

(Manuscript received February 10, 1992.) 